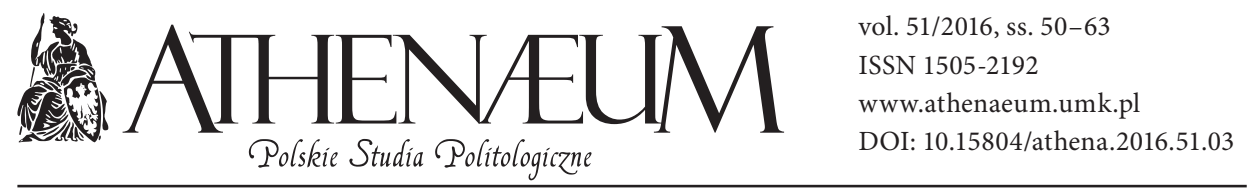

\title{
OD LINIOWOŚCI DO ZŁOŻONOŚCI. NOWY PARADYGMAT W NAUKACH SPOŁECZNYCH I POLITYCZNYCH
}

\author{
FROM LINEARITY TO COMPLEXITY. A NEW PARADIGM \\ IN SOCIAL AND POLITICAL SCIENCES
}

Monika Wichłacz*

\begin{abstract}
ABSTRAKT
Artykuł stanowi krótkie omówienie zagadnienia złożoności w naukach społecznych i politycznych. Zawiera refleksję dotyczącą paradygmatycznych wyzwań, przed jakimi stoi dyscyplina nauk społecznych, które zostały zaprezentowane w Raporcie Komisji Gulbenkiana na rzecz restrukturyzacji nauk społecznych. Postuluje on przełamanie przestarzałego podziału pomiędzy naukami przyrodniczymi i społecznymi oraz wprowadzenie bardziej holistycznego, interdyscyplinarnego podejścia do badanych zjawisk, struktur i procesów. W artykule staram się dowieść, że jest to możliwe do osiągnięcia dzięki szerszej adaptacji paradygmatu złożoności. Zostały przedstawione podstawowe założenia teorii złożoności, zwłaszcza w kontekście jej relacji z teorią chaosu, oraz cechy węzłowe systemów złożonych. Ponadto zarysowano także pewne wątki złożoności obecne w badaniach politologicznych.
\end{abstract}

Słowa kluczowe: złożoność, systemy złożone, liniowość, nauki społeczne, politics
The article provides a brief overview of the concept of complexity in social and political sciences. It reflects upon paradigmatic challenges for the discipline of social sciences, formulated in Gulbenkian Commision Report, that promotes moving past the obsolete divisions between natural and social sciences and advocates more holistic interdisciplinary outlook on social phenomena. The complexity paradigm is proposed as such an approach. Hence, key features of complexity theory and fundamental properties of complex systems are described. Also, some embodiments of themes of complexity paradigm in political research are outlined.

Keywords: complexity, complex systems, linearity, social sciences, politics

\footnotetext{
* Uniwersytet Wrocławski, Instytut Politologii.
} 
Paradygmat złożoności nie jest tylko przemijającą modą, atrakcyjną metaforą czy chwytliwym hasłem, ale niesie w sobie znaczny potencjał wyjścia poza ograniczenia tradycyjnych metod opisu i interpretacji świata społecznego i politycznego. Nie tylko odzwierciedla ducha czasu, ale stymuluje, słowami Emiliana Kavalskiego (2007), ,analityczną wyobraźnię” (s. 435), która owocuje wielością i nowatorstwem narzędzi opisu wielopoziomowości i dynamiki procesów społecznych oraz politycznych. Niepewnie jeszcze osadzony w naukach politycznych, także na gruncie polskiej politologii nie uzyskał on niestety szerszej recepcji, choć warto oczywiście wspomnieć dorobek Agnieszki Rothert (2006, 2007, 2008), Jakuba Potulskiego (2015) czy prace Filipa Pierzchalskiego (2011,2013), w których wątki złożoności są także obecne. Pomimo to potencjał „żywotności” i szanse na rozwój tego paradygmatu dostrzegam nie tylko w nowoczesności i interdyscyplinarności stosowanych instrumentów (zob. Richards, 2000) i w samych źródłach, podstawowych zasadach oraz głównych motywach jego funkcjonowania: trafności identyfikacji paradygmatycznych wyzwań, przed jakimi stają nauki społeczne, adekwatności podstawowych założeń teoretycznych systemów złożonych oraz różnorodności obszarów, tutaj na przykładzie nauk politycznych, w których wątki złożoności i założenia jej teorii znajdują odzwierciedlenie.

\section{DWIE WIZJE NAUK SPOŁECZNYCH}

Wyłonienie się koncepcji złożoności (complexity) stało się możliwe dzięki rewolucji, jaka miała miejsce w naukach ścisłych w XX wieku, która podważyła takie ich oświeceniowe fundamenty, jak newtonowska logika linearności, porządku, determinizmu i niezmienności praw, wraz z kartezjańskimi ideami dualizmu i redukcjonizmu. Teoria względności Einsteina, mechanika kwantowa Bohra czy zasada nieoznaczoności Heisenberga przekroczyły ograniczenia rozumienia i badania rzeczywistości nałożone przez tezy Newtona i Kartezjusza (Geyer, 2003, s. 565-566). Ta rewolucja teoretyczna oraz towarzyszący jej gwałtowny rozwój technik komputerowych umożliwiły skuteczne badanie i tworzenie modeli zachowań oraz dynamiki bardzo rozległych i wieloelementowych obiektów, przez co przyczyniły się do rozkwitu między innymi takich dziedzin, jak badania sieci neuronowych, sztucznej inteligencji czy teoria chaosu. Jednocześnie podjęto próby wykorzystania ich ustaleń do efektywnego badania „spontanicznej, samoorganizującej się dynamiki świata” (Waldrop, 1992, s. 13), które pozwoliłoby na wyjaśnianie zjawisk ekonomicznych, społecznych i politycznych. Przykładem 
takich wysiłków było uformowanie się w 1984 r. Santa Fe Institute, którego celem jest refleksja nad "wyłaniającymi się syntezami w nauce" i prowadzenie badań nad dużą liczbą wysoce złożonych i interdyscyplinarnych systemów, które mogą być właściwie dociekane jedynie w środowisku interdyscyplinarnym (Mitchell, 2009, s. x).

Podobną drogę można także dostrzec w wyłanianiu się postulatu złożoności w naukach społecznych. Wyrósł on z krytyki zbyt daleko idących prób zaadaptowania metod badawczych stosowanych w naukach ścisłych oraz kreślonej przez nie wizji świata wiedzionego obserwowalnymi i niezmiennymi prawami, gdzie zjawiska i procesy społeczne oraz polityczne traktowane są jako zjawiska linearne i przez to możliwe do przewidzenia. Państwom, społeczeństwom, a nawet jednostkom można wyznaczyć zatem pożądane stany końcowe i tak projektować polityki i strategie, by do tych stanów czy form w sposób racjonalny doprowadzić (Geyer, 2003, s. 568). Wątki takiego mechanicystycznego myślenia są na przykład obecne w podejściach badawczych, które skupiają się na atrybutach podmiotów jako czynnikach wyjaśniających ich zachowania i wybory. Ich agregowanie, poszukiwanie wspólnych bądź przypisanych dla danej kategorii zachowań sprzyja zaniedbywaniu strukturalnego i dynamicznego wymiaru relacji pomiędzy podmiotami i skłania badaczy do interpretowania zachowań społecznych jako zjawisk determinowanych normatywnie (Wellman, 1988, s. 31). Także teoria racjonalnego wyboru i racjonalnego aktora wskazuje, że zachowania i decyzje podmiotów są zewnętrznie determinowane i tym samym przewidywalne.

Niemożność znalezienia skutecznych narzędzi pozwalających na badanie złożonych i dynamicznych zjawisk życia społecznego, jak i niedostatek odpowiedniego aparatu pojęciowego sprawiły, że badaczom pozostało raczej skupienie uwagi na elementach niepodlegających przemianom i podejściu synchronicznym - opisie bieżącego stanu rzeczy oraz tworzeniu typologii (Winkowska-Nowak, Batorski, Peitgen, 2003, s. 1) zbyt szerokie wykorzystanie metod ilościowych (McKie, 2001, s. 81, za: Gilpin, Murphy, 2008, s. 23), nakierowanie badań głównie na wyjaśnianie, ale nie rozumienie zjawisk, uprzywilejowanie struktury nad podmiotowością, stałości nad zmianą oraz wyznaczanie sztucznych i arbitralnych podziałów (jak np. na politykę wewnętrzną i zagraniczną czy rozdzielanie sfery politycznej i ekonomicznej) - analitycznie wygodnych, ale zubażających refleksję badawczą (Smith, 2004).

Także w naukach politycznych posłużono się argumentem złożoności, by zerwać z pozytywistyczną „,wizją społeczeństwa opartego na porządku, prawach i postępie" (Geyer, Rihani, 2010, s. 5, za: Cairney, 2012, s. 347), twierdząc, że o ile 
„ilościowe i redukcjonistyczne metody i metodologie” mogą być skutecznie wykorzystywane np. w badaniu wyborów, zwłaszcza w kontekście ich „reguł i uporządkowanych struktur", ale nie zjawisk, które mieszczą w sobie wysoki poziom ryzyka, niepewności i niejednoznaczności (Geyer, Rihani, 2010, s. 74-75, za: Cairney, 2012, s. 347), czy czynników, które znajdują się poza kontrolą decydentów politycznych (policy makers) (Room, 2011, s. 6-7, za: Cairney, 2012, s. 347).

Coraz bardziej paląca stawała się potrzeba zastosowania „bardziej »mobilnego « podejścia teoretycznego" (Diken, 1998, s. 248, za: Urry, 2009, s. 35) poprzez przywrócenie „czasu i przestrzeni jako wewnętrznych zmiennych konstytutywnych dla (...) analiz, zamiast tylko niezmiennej rzeczywistości fizycznej, w obrębie której świat społeczny istnieje" (Wallerstein, 1999, s. 80). Umożliwia to efektywne badanie dynamiki zjawisk społecznych i politycznych, zwłaszcza na poziomie globalnym, co przy wykorzystaniu tradycyjnych metod było utrudnione, o ile w wielu przypadkach niemożliwe.

Sztywność metodologiczna i substancjalna nauk społecznych, oparcie ich na takich tradycyjnych kategoriach jak społeczeństwo, zwłaszcza że zwykle było ono ograniczone do kontekstu państwa narodowego, stawała się coraz bardziej dysfunkcjonalna w globalizującym się świecie mobilnych podmiotów, rozluźniających się więzi strukturalnych, wzrastającej złożoności sieci wymiany, governance, wielorakości ról i identyfikacji politycznych. Statycznym pojęciom, jak struktura czy pozycja, przeciwstawiane są takie kategorie, jak: sieci, pływy i mobilność, trafniej oddające płynność i dynamikę zjawisk społecznych (Urry, 2009, za: McLennan, 2003, s. 553-555). Staje się więc „imperatywem, by śledzić mianujące się formy ruchu, interakcji, subiektywności, governmentality, które ten rozległy proces zawiera" (McLennan, 2003, s. 554).

Debata dotycząca postulatów odejścia od linearnego, redukcjonistycznego oblicza nauk społecznych otrzymała nowy impet po publikacji Raportu Komisji Gulbenkiana na Rzecz Restrukturyzacji Nauk Społecznych, która postulowała, aby dyskusja i zmiana wewnątrz dyscypliny były zogniskowane wokół czterech wątków wiodących w tradycyjnej organizacji struktur wiedzy społecznej:

- ontologiczna odrębność między człowiekiem a naturą;

- państwo wyznacza jedyne i/lub możliwe granice zachodzenia i analizy działania społecznego;

- brak akceptacji dla nieustającego napięcia między partykularyzmem i uniwersalizmem, jednostką a zbiorowością oraz traktowanie ich jako anachronizmu; 
- pozytywistyczna koncepcja neutralności i obiektywności naukowej (Wallerstein,1999, s. 81).

Przede wszystkim rekomendowano przekreślenie przestarzałego według autorów podziału nauk na przyrodnicze i społeczne, który dodatkowo „utracił wymiar 'równości w odmienności' i nabrał posmaku hierarchii” (Wallerstein,1999, s. 19). Zerwania takiego można dokonać dzięki dostrzeżeniu w tych dwóch sferach właśnie cech złożoności, porzuceniu „pojmowania ludzkości jako mechanizmu, lecz raczej w to miejsce (...) pojmowanie przyrody jako aktywnej i twórczej” (Wallerstein,1999, s. 68) i uczynieniu idei praw natury spójnej „z ideą zdarzeń, nowości kreatywności” (Wallerstein,1999, s. 69). Pozwoli to na analizę naukową opartą "na dynamice nie-ekwilibrów, kładącą nacisk na mnogość cech, bifurkację i wybór, historyczną zależność oraz - dla niektórych - immanentną i nieodłączną niepewność" (Wallerstein,1999, s. 68).

W raporcie sformułowano postulat złożoności w następujący sposób: „Historyczne systemy społeczne składają się najwyraźniej z wielu na siebie oddziałujących jednostek, charakteryzujących się emergencją i ewolucyjnością hierarchicznej organizacji i struktury (zagnieżdżonych w tych systemach) oraz złożonym zachowaniem przestrzenno-czasowym. Co więcej, oprócz tego typu złożoności okazywanej przez nielinearne, dynamiczne systemy ze stałymi mechanizmami interakcji mikroskopowej, historyczne systemy społeczne składają się z pojedynczych elementów zdolnych do wewnętrznej adaptacji i uczenia się wskutek doświadczenia. Dodaje to nowy poziom złożoności (wspólny z biologią ewolucyjną i ekologią, wykraczający poza poziom nielinearnej dynamiki tradycyjnych systemów fizycznych)" (Wallerstein,1999, s. 69).

Wyłania się obraz relacji społecznych jako mających niestabilny (będących na krawędzi chaosu), hybrydowy (pomiędzy światem fizycznym i społecznym) charakter, oparty na „poczuciu przypadkowej otwartości, wielorakości stanów przyszłych, nieprzewidywalności wyników w czasoprzestrzeni, docenieniu roli obiektów nieożywionych i przyrody, różnorodnych nielinearnych przemian w relacjach, rodzinach i osobach na ogromnych obszarach w czasie i przestrzeni, systemowej naturze procesów oraz wzrastającej hiperzłożoności organizacji, produktów, technologii i socjalności” (Urry, 2005, s. 3).

Takie ujęcie nie oznacza oczywiście całkowitego odrzucania lineraności i porządku jako elementów składowych zjawisk społecznych i politycznych. Zachęca jednak uczonych do inkorporowania w swoje badania wątków chaosu, emergencji i złożoności jako konstytutywnych dla analizowanego obszaru, i dążenia przez nich przede wszystkim do rozumienia obrazu złożonych inte- 
rakcji i systemów, a nie poszukiwania porządku i przewidywalności zjawisk i procesów (Greyer, 2003, s. 569).

Syntetyczne porównanie dominujących wątków w koncepcjach linearności i złożoności przedstawił Robert R. Geyer ${ }^{1}$.

Tabela 1. Linearność vs złożoność

\begin{tabular}{|l|l|l|}
\hline \multicolumn{1}{|c|}{ Wątek } & \multicolumn{1}{|c|}{ Linearność } & \multicolumn{1}{c|}{ Złożoność } \\
\hline Pozycje epistemologiczne & $\begin{array}{l}\text { Porządek } \\
\text { Racjonalność } \\
\text { Przewidywalność } \\
\text { Redukcjonizm } \\
\text { Determinizm } \\
\text { Nie-interpetatywna }\end{array}$ & $\begin{array}{l}\text { Częściowy porządek } \\
\text { Ograniczona racjonalność } \\
\text { Przewidywalność i niepewność } \\
\text { Redukcjonizm i holizm } \\
\text { Probalizm i emergencja } \\
\text { Interpretatywna }\end{array}$ \\
\hline $\begin{array}{l}\text { Relacja pomiędzy naukami } \\
\text { fizycznymi i społecznymi }\end{array}$ & $\begin{array}{l}\text { Uległość i podporządkowanie } \\
\text { nauk społecznych. Muszą one } \\
\text { dążyć do powielania metod } \\
\text { i rezultatów nauk fizycznych. }\end{array}$ & $\begin{array}{l}\text { Relacja integratywna. Separacja } \\
\text { pomiędzy naukami fizycznymi } \\
\text { i społecznymi nie jest konieczna. }\end{array}$ \\
\hline $\begin{array}{l}\text { Relacja } \\
\text { pomiędzy człowiekiem i naturą }\end{array}$ & $\begin{array}{l}\text { Rozszerzanie ludzkiej dominacji } \\
\text { nad naturą. }\end{array}$ & $\begin{array}{l}\text { Holistyczna interpretacja koewo- } \\
\text { lucji człowieka i natury. }\end{array}$ \\
\hline Implikacje metodologiczne & $\begin{array}{l}\text { Eksperyment i kwantyfikacja, po- } \\
\text { szukiwanie praw podstawowych. }\end{array}$ & $\begin{array}{l}\text { Integracja eksperymentu } \\
\text { i interpretacji. Prawa podstawowe } \\
\text { i dystynktywne rezultaty. }\end{array}$ \\
\hline Wizja postępu & $\begin{array}{l}\text { Znaczące ograniczenia dla władzy } \\
\text { brak inherentnych ograniczeń dla }\end{array}$ & $\begin{array}{l}\text { Znatępu z powodu złożoności } \\
\text { i postego poznania i postępu. } \\
\text { i niepewności. }\end{array}$ \\
\hline
\end{tabular}

Źródło: "Globalization, Europeanization, Complexity, and the Future of Scandinavian Exceptionalism" R.R. Geyer, 2003, "Governance: An International Journal of Policy, Administration, and Institutions”, Vol. 16, No. 4, s. 569.

1 Autor przedstawia w swojej tabeli różnice pomiędzy linearnością, złożonością i postmodernizmem, jednak ze względu na zakres tematyczny tego artykułu wykorzystałam tylko dwa pierwsze elementy. 


\section{SYSTEMY ZŁOŻONE}

Badanie systemów złożonych odchodzi od ujęcia redukcjonistycznego (choć go całkowicie nie porzuca) na rzecz holizmu. Ponownie kieruje naszą uwagę na analizę systemową, negując jednocześnie kilka jej kluczowych założeń - przede wszystkim tezę o równowadze systemu jako celu/naturalnego stanu jego istnienia oraz jego linearność, która zakłada równowagę liczby wejść i wyjść systemu i proporcjonalność zachodzących w nich zmian (Beyerchen, 1989, s. 30, za: Jervis, 1997, s. 22).

Stanem naturalnym systemu złożonego jest brak równowagi, „chaos, odrzucenie idei porządku jako idei wyjściowej lub docelowej" (Hałas, 2011, s. XII, XXVIII). Teoria złożoności jest więc zwykle łączona z teorią chaosu (Blaikie, 2007, s. 207) i obie uważane za składniki jednego paradygmatu (Urry, 2003, za Blaikie, 2007, s. 207). Podzielają one rozumienie samego pojęcia chaosu, który jest „konceptualizowany jako w najwyższym stopniu złożona informacja, a nie nieobecność porządku" (Hayles, 1991, s. 1, za: Byrne, 1998, s. 16). Takie podejście zawiera element determinizmu i pozwala na śledzenie, choć na odmienny sposób i przy użyciu innych metod, także działań celowościowych (Byrne, 1998, s. 16-17). N. Katherine Hayles (1990, 1991, za Byrne, 1998, s. 16) zwraca przy tym uwagę na nieadekwatność zakorzenionej w zachodnim sposobie myślenia dychotomii chaosu, rozumianego jako brak porządku (disorder). Przeciwstawia logikę binarną logice czterowartościowej (obecnej na przykład w tradycji taoistycznej), w której nie-porządek nie równa się anty-porządkowi. O ile w praktycznym użyciu chaos można więc, według autorki, rozumieć po prostu jako przypadkowość, to użycie naukowe odnosi go do nie-porządku i postrzega go jako zawierający w sobie i/lub poprzedzający porządek. Systemy emergentne są właśnie przykładami takiego chaosu, gdzie powiązanie pomiędzy determinizmem a przewidywalnością zostało zerwane (wprawdzie bardziej w sensie metaforycznym niż technicznych aspektów zastosowania teorii chaosu) (Nowotny, Scott, Gibbons, 2001, s. 5-7, za: Nowotny, 2005, s. 16). Należy przy tym jednak pamiętać, że nie wszystkie systemy złożone mają chaotyczny charakter i vice versa.

Wkład teorii chaosu w rozwój koncepcji złożoności jest jednak przez niektórych uczonych uważany za ograniczony. Według Paula Cilliersa (1998, s. ix, za Blaikie, 2007, s. 207) nie należy przeceniać jej znaczenia w wyjaśnianiu funkcjonowania systemów złożonych, zwłaszcza w kontekście ich wrażliwości na warunki początkowe - rozbudowana natura systemów złożonych pozwala 
im na działanie w ten sam sposób przy oddziaływaniu różnych warunków, co zapewnia im przetrwanie. Jest to zauważalne w dociekaniach Duncana J. Wattsa (2002), dotyczących wrażliwości systemów złożonych (w przypadku jego badań - sieciowych) na występowanie globalnych kaskad, gdzie autor dowiódł, że systemy złożone pod pewnymi warunkami mogą być bardzo wrażliwe, ale też i odporne na ten sam bodziec inicjujący o średniej mocy. Dla Williama A. Sherdena (1992, s. 69, za: Blaikie, 2007, s. 207) chaos jest w pełni kierowany prawami nieliniowości, podczas gdy systemy złożone stanowią porządki wyłaniające się ze złożonych interakcji pomiędzy elementami systemu, opartych na jednej lub dwóch wiodących zasadach i organizujących się bez zewnętrznej kontroli. Teoria złożoności różni się od teorii chaosu także tym, że - jak zauważa Mark. C. Taylor (2003) - w mniejszym stopniu skupia się na kwestii nieuchronności wystąpienia chaosu, czyli zaburzenia w funkcjonowaniu systemu. Badacz umieszcza złożoność pomiędzy (podkreślenie autora) porządkiem a chaosem. Moment wystąpienia złożoności stanowi dla niego „punkt, w którym samoorganizujące się systemy wyłaniają się, by tworzyć nowe wzorce koherencji i struktur relacji” (s. 24).

Badanie systemów złożonych odpowiada postulatowi dynamicznego minimalizmu. Poszukiwaniom najprostszych wyjaśnień, najbardziej podstawowych zasad wspólnych dla systemów oraz dla zachodzących w nich zjawisk, które występują w systemie powtarzalnie, towarzyszą dociekania, w jaki sposób interakcje pomiędzy najprostszymi elementami systemu prowadzą do wyłonienia się złożoności, którą obserwujemy dopiero na poziomie systemu jako całości (Nowak, 2009, s. 12). Powstaje zjawisko emergencji, która oznacza „pojawianie się na poziomie systemu właściwości, których nie ma na poziomie elementów, i których na podstawie samych elementów nie można by oczekiwać" (Nowak, 2009, s. 12).

O istnieniu systemu złożonego decyduje więc takie połączenie jego elementów, że zmiana w jednym $\mathrm{z}$ nich, lub zmiana relacji pomiędzy pewnymi częściami systemu wywołuje zmiany w innych jego częściach oraz fakt, że system ma charakter nielinearny - cechy systemu jako całości, zachowania lub ich rezultaty, nie mogą być rozumiane tylko jako suma cech, zachowań i rezultatów zachowań jego części (Jervis, 1997, s. 20). Sam system nie może zostać zatem „zredukowany do elementarnych praw czy prostych procesów" (Urry, 2005, s. 3). O ile więc wyjaśnienia zjawisk na poziomie elementów mogą wydawać się trywialne, na poziomie emergencji prowadzą do pojawienia się zaskakujących, złożonych właściwości (Nowak, 2009, s. 13). Nieliniowość systemu tworzy sytuację, w której 
niewielkie stany początkowe mogą wywołać nieproporcjonalnie duże skutki i vice versa (Urry, 2009, s. 169). Dynamika zachowań podmiotów nie może być więc wyjaśniona jedynie poprzez prostą logikę przyczynowo-skutkową, w której da się uchwycić określony zespół przyczyn i odpowiadający im zestaw skutków (Jervis, 1997, s. 24).

Systemy złożone zwykle posiadają olbrzymią liczbę elementów, co przesądza o nieadekwatności formalnych sposobów reprezentacji (Urry, 2009, s. 171). Są to przeważnie systemy otwarte, to znaczy wchodzące w interakcje $\mathrm{z}$ ich otoczeniem. Stąd trudno określić ich granice - są one zwykle określane przez samego badacza ze względu na potrzebę możliwości opisu systemu, a więc wyznaczone jego perspektywą (Cilliers, 1998, s. 4).

Elementy systemu oddziałują na siebie w czasie fizycznie i informacyjnie (Urry, 2009, s. 171). Interakcje mają gęsty (rich) (każdy element wpływający na system jest poddawany wpływowi dużej liczby innych elementów) i dynamiczny charakter. Zachowanie systemu nie jest jednak determinowane przez liczbę interakcji powiązanych z określonym elementem (Cilliers, 1998, s. 3). Interakcje są oparte na informacji przenoszonej na relatywnie lokalnym polu, dlatego funkcjonują w warunkach dalekich od równowagi (Urry, 2009, s. 171). Elementy systemu nie posiadają wiedzy na temat jego zachowania jako całości - w innym wypadku cała złożoność systemu (co jest fizycznie niemożliwe) i jego „świadomość” (co jest „metafizycznie” niemożliwe) byłyby obecne w każdym z tych elementów. Nie wyklucza to oczywiście wpływu o szerokim zasięgu, przy czym gęstość interakcji powoduje, że „tor” wpływu pomiędzy elementami może być odtworzony jedynie w kilku krokach. Taka pośredniość i rozproszenie oddziaływania wpływa na jego przekształcenie (modulation) - wzmocnienie, stłumienie lub inne różnorakie zmiany (Cilliers, 1998, s. 4-5).

Systemy złożone posiadają pętle pozytywnego i negatywnego sprzężenia zwrotnego. W przeciwieństwie do negatywnych sprzężeń zwrotnych korygujących zakłócenia w systemie dążącym do homeostazy (których znaczenie podkreślano w teoriach systemu od lat 40. do 70. ubiegłego wieku), w systemach nielinearnych szczególne znaczenie posiadają pozytywne sprzężenia zwrotne, które nasilają początkowe zakłócenie, stres występujący w systemie, co uniemożliwia absorbowanie wstrząsów i przywrócenie stanu równowagi (Urry, 2005, s. 5). Prowadzi to do samowarunkujących się ścieżek rozwoju (path dependence), w których „przyczynowość przepływa od przypadkowych wydarzeń do generalnych procesów, od niewielkich bodźców do rozległych efektów systemowych, od historycznie i terytorialnie odległych lokalizacji do całości” (Urry, 2005, s. 6). 
Ujawnienie się pewnego ładu w ogólnym nie-porządku wiąże się z efektem „dziwnych atraktorów”, które generują drobne wahania w stanach wyjściowych, gdy iteracja powtarza się i tworzy się ustrukturyzowany nie-porządek (Urry, 2009, s. 169).

Systemy złożone oddziałują dysypatywnie z otoczeniem - są zdolne do przyswajania wielkich ilości energii z otoczenia i przetwarzania jej na coraz większą strukturalną złożoność. Jednocześnie oddają środowisku znaczne ilości pozostałej energii, a proces ten jest nieodwracalny. Osiągany jest wtedy punkt bifurkacji, w którym tworzą się nowe formy porządku i w którym ich przyszłe zachowanie i przyszłe tory ruchu stają się nieprzewidywalne - wyłaniają się wtedy nowe struktury wyższego rzędu i wyższej złożoności (Urry, 2009, s. 170). Równowaga nie jest więc celem systemu czy warunkiem jego przetrwania. Przeciwnie, równowaga oznacza „śmierć” systemu. W analizie systemów nie można zatem ignorować ich wymiaru czasowego - ewoluują one w czasie, a ich przeszłość jest współodpowiedzialna za ich późniejsze zachowanie i przyszłość, stanowi on tym samym konieczny element wyjaśniający (Cilliers, 1998, s. 4).

Podsumowując, sposób funkcjonowania systemów złożonych zakłada nieliniowość, płynność czasu, nierozdzielność systemów i ich otoczenia oraz zdolność do autopojetycznego wyłaniania z siebie nowego porządku (Capra, 1996, s. 187 za: Urry, 2009, s. 171).

\section{ZŁOŻONOŚĆ POLITYKI}

David Byrne (2005) definiuje złożoność jako „interdyscyplinarne rozumienie rzeczywistości, jako zbudowanej z wielu złożonych, otwartych systemów o właściwościach emergentnych i potencjale transformacyjnym" (s. 97). Jej wewnętrzna różnorodność, zawierająca cały wachlarz inspiracji i odniesień - od nauk ścisłych po literaturoznawstwo ${ }^{2}$ - sprawia, że także w naukach politycznych nie tworzy spójnej teorii, ale raczej luźne podejście badawcze, czy zestaw teoretycznych lub konceptualnych narzędzi, służące do wyjaśniania rzeczywistości politycznej. Złożoność może być rozumiana jako pewien sposób myślenia o polityce, zestaw przekonań lub orientacja ideologiczna (Harrison, 2006, s. 2). Włączanie dużych i różnorodnych obszarów aktualnej wiedzy do podejścia „złożonościowego”

\footnotetext{
2 Pewne elementy teorii złożoności zyskują także bardzo dużą popularność w popkulturze, jak np. słynny „efekt motyla” wywodzący się z teorii chaosu.
} 
daje nadzieję na ciągłe powstawanie nowych, przydatnych metod badawczych i generowanie radykalnie odmiennych propozycji rozwiązania problemów politycznych (Harrison, 2006, s. 3). Jedną z takich prób jest wprowadzenie kategorii sieci (zob szerzej: Rothert, 2007, Wichłacz, 2012) konceptualizowanej jako obiekt dynamiczny i ewoluujący, będący strukturą rozproszonych, zmiennych systemów, złożoną z wielopoziomowych, przecinających się i nakładających się na siebie relacji, łączących w sobie porządek i przypadkowość (Rothert, 2007, s. 193, 195). Podejście sieciowe daje możliwości efektywnego badania struktur i relacji politycznych w ich dynamicznym wymiarze, $\mathrm{z}$ takimi leitmotivami, jak: mobilność, przepływ, zmiana, ruch, emergencja, tymczasowa strukturyzacja form. Dostarcza także sposobów wyjaśniania wielu nieoczekiwanych rezultatów politycznych, procesów oraz związków organizacyjnych, które są trudne do wyjaśnienia przez inne kategorie, jak np. hierarchie i rynki.

Zastosowanie paradygmatu złożoności jest widoczne przede wszystkim w dziedzinie stosunków międzynarodowych, polityki publicznej i policy making, zwłaszcza w problematyce governance, w tym w wyjaśnianiu takich współczesnych zjawisk politycznych, jak: zamazywanie się granic między tym, co publiczne i prywatne, wewnątrzpaństwowe i międzynarodowe; decentralizacja rządzenia, w tym przeprowadzanie kwestii politycznych niejako obok, niezależnie lub równolegle do głównej osi polityki przedstawicielskiej czy hierarchii instytucji politycznych; „fragmentaryzacja” państwa przy jednoczesnym zwiększaniu się zakresu państwowego policy making; sektoryzacja policy making; rządzenie wielopoziomowe, złożone i jednoczesne niestabilne, mieszczące w sobie kombinacje rywalizacji i koordynacji, negocjacji i egzekwowania władzy, niezależności i współzależności; nowe sposoby mobilizacji konkurencyjnych interesów, wzrost liczby podmiotów procesów decyzyjnych, co może prowadzić do „przepełnionego” policy making; strategie i sposoby funkcjonowania organizacji pozarządowych oraz strategie przyjmowane w oddolnej polityce „,sieci sprzeciwu”, ,twitterowych rewolucjach” itp.; czy wreszcie budowanie polityki w coraz większym stopniu poprzez negocjacje i porozumienia, poprzez koordynację, a nie nakaz i kontrolę, dzięki czemu mogą tworzyć się stabilne, ale łatwe w adaptacji układy oparte na wzajemnym zaufaniu i/lub wspólnych zasadach (Thompson, 2010, s. 141-160, Schmidt, 2007, s. 894, za: Wichłacz, 2012, s. 121-122).

W takiej analizie przewija się wątek polityki bez centrum, bez wyznaczonych granic, „materializującej się w różnych ramach i kontekstach” (Bentivegna, 2006, s, 334). Gdzie struktura społeczna „pojawia się” jako mieszanina porządku i przypadkowości, hierarchii i heterarchii. Gdzie ład może więc wyłaniać się zarówno 
odgórnie i centralistycznie, a także w wyniku oddolnych, spontanicznych, rozproszonych i zdecentralizowanych interakcji jednostek (Fukuyama, 1999; Rothert, 2007, s. 193). Wzrasta zainteresowanie sprawczością i strategicznymi działaniami aktorów, poruszających się w świecie ryzyka, „czarnych łabędzi” i „efektów kaskadowych”. Władza interpretowana jest w kategoriach relacyjnych, a rola, jaką spełnia państwo, jest ograniczona, nieklarowna, płynna i nieprzesądzona. Wyłaniają się nowe obszary „robienia polityki”, które przekraczają granice pomiędzy technologią, społeczeństwem, przyrodą, kulturą i ekonomią, a działania i strategie polityczne pojawiają się w nowych konfiguracjach, które nie wpasowują się już w tradycyjne struktury, formaty i kody. Polityka ciągle „wyłania się”, przemieszcza, traci i zyskuje od nowa swój kształt.

\section{BibLIOGRAFIA:}

Bentivegna, S. (2006). Rethinking Politics in the World of ICTs. European Journal of Communication, Vol. 21, No. 3, s. 331-343. DOI: 10.1177/0267323106066638.

Beyerchen, A. (1989). Nonlinear Science and the Unfolding of a New Intellectual Vision. W: R. Bjornson, M.R. Waldman (red.). Rethinking Patterns of Knowledge (Papers in Comparative Studies, Vol. 6) (s. 369-392.). Columbus: Center for Comparative Studies in the Humanities, Ohio State University Press.

Blaikie, N. (2007). Approaches to Social Enquiry: Advancing Knowledge. Cambridge: Polity.

Byrne, D.S. (1998). Complexity Theory and The Social Sciences: An Introduction, London, New York: Routledge.

Byrne, D.S. (2005). Complexity, Configuration and Cases. Theory, Culture \& Society, Vol. 22, No. 5, s. 95-11. DOI: 10.1177/0263276405057194.

Cairney P. (2012). Complexity Theory in Political Science and Public Policy. Political Studies Review, Vol. 10, No. 3, s. 346-358. DOI: 10.1111/j.1478-9302.2012.00270.x. Capra, F. (1996). The Web of Life, London: Harper Collins.

Cilliers, P. (1998). Complexity and Postmodernism. Understanding Complex Systems, London and New York: Routledge.

Diken, B. (1998). Strangers, Ambivalence and Social Theory. Aldershot: Ashgate.

Fukuyama, F. (1999). The Great Disruptions: Human Nature and the Reconstruction of Social Order. New York: Free Press.

Geyer, R.R. (2003). Globalization, Europeanization, Complexity, and the Future of Scandinavian Exceptionalism. Governance: An International Journal of Policy, Administration, and Institutions, Vol. 16, No. 4, s. 559-576. DOI: 10.1111/1468-0491.00228.

Geyer, R.R., Rihani, S. (2010). Complexity and Public Policy: A New Approach to 21 $1^{\text {st }}$ Century Politics, Policy And Society. London: Routledge. 
Gilpin, D.R., Murphy, P.J. (2008). Crisis Management in a Complex World. New York: Oxford University Press.

Hałas, E. (2011). Wprowadzenie. Sieci społeczne i znaczenia: Harrisona C. White’a teoria procesów socjokulturowych. W: H.C. White. Tożsamość i kontrola. Jak wyłaniaja się formacje społeczne (s. XIII-XL). Kraków: Nomos.

Harrison, N.E. (2006). Thinking About the World We Make. W: N.E. Harrison (red.), Complexity in World Politics. Concepts and Methods of a New Paradigm (s. 1-23). New York: State University of New York.

Hayles, N.K. (1990). Chaos Bound: Orderly Disorder in Contemporary Literature and Science. Ithaca and London: Cornell University Press.

Hayles, N.K.(1991). Introduction: Complex Dynamics in Literature and Science. W: N.K., Hayles (red.). Chaos and Order: Complex Dynamics in Literature and Science (s. 1-36). Chicago and London: University of Chicago Press.

Jervis, R. (1997). Complex Systems: The Role of Interactions. W: D.S. Alberts, T.J. Czerwinski (red.). Complexity, Global Politics, and National Security (s. 20-31). Washington: National Defense University.

Kavalski, E. (2007). The Fifth Debate and the Emergence of Complex International Relations Theory: Notes on the Application of Complexity Theory to the Study of International Life. Cambridge Review of International Affairs, Vol. 20, No. 3, s. 435-454. DOI: 10.1080/09557570701574154.

McKie, D. (2001). Updating Public Relations: “New Science," Research Paradigms, and Uneven Developments. W: R.L. Heath, G. Vasquez (red.). Handbook of Public Relations (s.75-92). Thousand Oaks: SAGE Publications.

McLennan, G. (2003). Sociology's Complexity. Sociology, Vol. 37, No. 3, s. 547-564. DOI: $10.1177 / 00380385030373009$.

Mitchell, M. (2009). Complexity. A Guided Tour. Oxford: Oxford University Press.

Nowak, A. (2009). Wstęp. Układy złożone w naukach społecznych. W: A. Nowak, W. Borkowski, K. Winkowska-Nowak (red.). Układy złożone w naukach społecznych. Wybrane zagadnienia (s. 9-16). Warszawa: Wydawnictwo Naukowe Scholar.

Nowotny, H. (2005). The Increase of Complexity and its Reduction: Emergent Interfaces between the Natural Sciences, Humanities and Social Sciences. Theory, Culture \& Society Vol. 22, No. 5, s. 15-3. DOI: 10.1177/0263276405057189.

Nowotny, H., Scott, P., Gibbons M.T. (2001). Re-thinking Science. Knowledge and the Public in an Age of Uncertainty. Cambridge: Polity.

Pierzchalski, F. (2011). Emergencja przestrzeni politycznej. Atheneum, Vol. 31, s. 18-35. Pierzchalski, F. (2013). Morfogeneza przywództwa politycznego. Pomiędzy struktura a podmiotowościa sprawcza. Bydgoszcz: Uniwersytet Kazimierza Wielkiego.

Potulski, J. (2015). Współczesne problemy badawcze politologii. Gdańsk: Uniwersytet Gdański.

Richards, D. (red.) (2000). Political Complexity: Nonlinear Models of Politics. Ann Arbor: University of Michigan Press.

Room, G. (2011). Complexity, Institutions and Public Policy: Agile Decision-Making in a Turbulent World. Cheltenham: Edward Elgar. 
Rothert, A. (2006). Między porządkiem a chaosem, Warszawa: Dom Wydawniczy Elipsa. Rothert, A. (2007). Sieciowy (bez)ład, czyli emergencja systemu politycznego. W: J. Szymanek, M. Kaczorowska, A. Rothert. Ewolucja, dewolucja, emergencja w systemach politycznych (s. 184-243), Warszawa: Elipsa.

Rothert, A. (2008). Emergencja rzadzenia sieciowego. Warszawa: Dom Wydawniczy Elipsa.

Schmidt, A. (2007). Social Networks Theory. W: M. Beevir (red.). Encyclopedia of Governance (s. 892-895), Thousand Oaks, London, New Delhi: SAGE Publications.

Sherden, W.A. (1997). The Fortune Sellers: The Big Business of Buying and Selling Predictions. Hoboken: John Wiley \& Sons.

Smith, S. (2004). Singing Our World into Existence: International Relations Theory and September 11, International Studies Quarterly, Vol. 48, No. 3, s. 499-515. DOI: 10.1111/j.0020-8833.2004.t01-1-00312.x.

Taylor, M.C. (2003). The Moment of Complexity. Emerging Network Culture, Chicago: The University of Chicago Press.

Thompson, G.F. (2010). Between Hierarchies \& Markets. The Logic and Limits of Network Forms of Organization, Oxford: Oxford University Press.

Urry J. (2000). Mobile Sociology. British Journal of Sociology, Vol. 51, No.1, s. 185-203. DOI: $10.1111 / j .1468-4446.2000 .00185 . x$.

Urry, J. (2003). Global Complexity, Cambridge: Polity.

Urry, J. (2005). The Complexity Turn. Theory, Culture, Society, Vol. 22, No. 1, s. 1-14. DOI: $10.1177 / 0263276405057188$.

Urry J. (2009). Socjologia mobilności. Warszawa: Wyd. Naukowe PWN.

Waldrop, M.M. (1992). Complexity. The Emerging Science at the Edge of Order and Chaos, New York: Simon \& Schuster.

Wallerstein, I. (1999). Otwórzmy nauki społeczne. Raport Komisji Gulbenkiana na rzecz restrukturyzacji nauk społecznych (s. 9-106). W: A. Flis (red.). Wyzwania wobec nauk społecznych u progu XXI wieku. Kraków: Universitas.

Watts, D.J. (2002). A simple Model of Global Cascades on Random Networks. Proceedings of the National Academy of Sciences of the United States of America. Vol. 99, No. 9, s. 5766-5771.

Wellman, B. (1988). Structural Analysis: From Method and Metaphor to Theory and Substance. W: B. Wellman, S.D. Berkowitz (red.), Social Structures: A Network Approach (s. 19-61). Cambridge: Cambridge University Press.

Wichłacz, M. (2012). Sieć a rozumienie przestrzeni polityki. W: A. Czajowski, L. Sobkowiak, (red.). Polityka i polityczność. Problemy polityczne i metodologiczne (s. 101-124). Wrocław: Atla 2.

Winkowska-Nowak, K., Batorski, D., Peitgen, H.-O. (2003). Wprowadzenie do dynamiki społecznej. Warszawa: Szkoła Wyższa Psychologii Społecznej. 